Научная статья

УДК 355/091

DOI: $10.18101 / 1994-0866-2021-3-27-35$

\title{
ФИЛОСОФИЯ ВОЙНЫ ПЛАТОНА
}

\author{
(C) Коробов-Латынцев Андрей Юрьевич \\ кандидат философских наук, \\ начальник кафедры гуманитарных дисциплин, \\ Донецкое высшее общевойсковое командное училище \\ Донецкая Народная Республика, 283005, г. Донецк, ул. Куприна, 1 \\ a.k-1@mail.ru
}

\begin{abstract}
Аннотация. В статье реконструируется философия войны Платона. Взросление знаменитого философа-идеалиста происходило во время войны его родного полиса со Спартой, поэтому вопрос о происхождении и природе войны занимает немаловажное место в его философии. Это отражается и в его построениях о государстве, и в этике, и даже в представлениях о человеке и его сущности. По Платону, в войне государство предстает в движении. Сами войны философ делит на внешние (с варварами) и внутренние (войны греков друг с другом). Внутренние войны философ рассматривает при помощи этических критериев, однако разговор о войнах внешних выстраивается на совершенно иных основаниях. При этом Платон рассматривает не только политическое и этическое измерение войны, но и онтологическое.
\end{abstract}

Ключевые слова: Платон, философия войны, внутренние и внешние войны, добродетель.

\section{Для цитирования}

Коробов-Латынцев А. Ю. Философия войны Платона // Вестник Бурятского государственного университета. Философия. 2021. Вып. 3. С. 27-35.

Уже на самых ранних этапах становления проекта античной философии его представители проявили интерес к такому феномену, как война. Война интересовала греческих мыслителей именно как философский объект. В качестве универсального первоначала определяет войну Гераклит Эфесский в фрагменте F 53: «Раздор - отец всех общий /И всех общий царь / И одних богами объявляет он / А других - людьми / Одних рабами сотворяет он / Других свободными». Внешне поэтизируя войну, философ ее онтологизирует, закрепляет за ней значение верховного закона вселенной. Без войны, по Гераклиту, всё исчезает: братство, мужество, любовь, сама мысль, иерархия. Без войны не рождается Гармония (фрагмент F 9A 1-4).

В дальнейшей истории греческой философии война будет важной темой, и не только темой теоретической, но и жизненной: Сократ, известно, единственный раз отлучался из своего родного полиса именно ради войны, причем на поле боя вел себя достойно (Платон описал мужественное поведение Сократа в бою в Пи$\left.\mathrm{pe}^{1}\right)$ [8, с. 180-181]; ученик Сократа Ксенофонт также принимал участие в бое-

${ }^{1}$ См. «Пир»: 220А, Алкивиад о Сократе: «Выносливостью он превосходил не только меня, но и вообще всех. Когда мы оказывались отрезанными и поневоле, как это бывает в 
вых действиях и даже командовал греческим войском (что впоследствии описал в своем труде «Анабасис»). Ученик Сократа Платон и его ученик Аристотель также будут много рассуждать о войне, ее природе, законах, ее типах [6]. И даже последний великий философ эллинского мира Плотин обмолвился о войне [14].

Эллинские философы не просто философствовали о войне, но при необходимости смело вступали в войну, т. е. буквально брали в руки оружие и воевали (Сократ), им даже случалось быть полководцами (Ксенофонт). Ниже рассмотрим построения о войне одного из самых влиятельных философов в мире - Платона.

Важным обстоятельством для реконструкции платоновской философии войны является тот факт, что годы взросления философа пришлись на Пелопонесскую войну (431-404 гг. до н. э.), которая по своему значению и по своим геополитическим последствиям сравнима для Древнего мира с мировой войной и которая по своей сути таковой и являлась. И сама война, и ее итог (родной полис Платона лишился былой мощи и славы) не могли не сказаться на мировоззрении философа.

Война, по Платону, позволяет увидеть государство в движении. О том идеальном государстве, которое описано в одноименном диалоге, Платон скажет в другом своем диалоге под названием «Тимей», что оно вызывает у него чувство, которое «испытываешь, увидев каких-нибудь благородных, красивых зверей, изображенных на картине, а то и живых, но неподвижных: непременно захочется поглядеть, каковы они в движении и как они при борьбе выявляют те силы, о которых с позволяет догадываться склад их тел» [13]. Именно поэтому, говорит в диалоге Сократ, для того чтобы в полной мере понять, как живет государство и каково оно в действительности, нужно увидеть, «как это государство ведет себя в борьбе с другими государствами, как оно достойным его образом вступает в войну, как в ходе войны его граждане совершают то, что им подобает, сообразно своему обучению и воспитанию, будь то на поле брани или в переговорах с каждым из других государств» [13].

походах, голодали, никто не мог сравниться с ним выдержкой. Зато когда всего бывало вдоволь, он один бывал способен всем насладиться». Пир 220Е: «А хотите знать, каков он в бою? Тут тоже нужно отдать ему должное. В той битве, за которую меня наградили военачальники, спас меня никто иной, как Сократ, не захотев бросить меняя, раненного, он вынес с поля боя и мое оружие, и меня самого»; 221 а-с: «Особенно же стоило посмотреть на Сократа, друзья, когда наше войско, обратившись в бегство, отступало от Делия. Я был тогда в коннице, а он в тяжелой пехоте. Он уходил вместе с Лахетом, когда наши уже разбрелись. И вот я встречаю обоих и, едва их завидев, призываю их не падать духом и говорю, что не брошу их. Вот тут-то Сократ и показал мне себя с еще лучше стороны, чем в Потидее, - сам я был в меньшей опасности, потому что ехал верхом. Насколько прежде всего было у него больше самообладания, чем у Лахета. Кроме того, мне показалось, что и там, так же как и здесь, он шагал, говоря твоими, Аристофан, словами, «чинно глядя то влево, то вправо», то есть спокойно посматривал на друзей и на врагов, так что даже издали каждому было ясно, что этот человек, если его тронешь, сумеет постоять за себя, благодаря чему оба они благополучно завершили отход. Ведь тех, кто так себя держит, на войне обычно не трогают, преследуют тех, кто бежит без оглядки». 
Эти слова Платона/Сократа можно интерпретировать в милитаристском смысле: человек невозможен без полиса, а полис, в свою очередь, невозможен без войны, поскольку именно война есть государство в движении. Действительно, ведь к чему, спрашивает Платон, все законы, все общественные устроения, театры и даже философия, если в любой момент на твой полис может напасть другое государство и превратить все это в прах? Однако не следует делать поспешные выводы о философии войны Платона и его личном отношении к войне.

Впрочем, о личном отношении Платона к войне он сам скажет в диалоге «Менексен». В этом диалоге есть знаменитые слова Сократа: «Право, Менексен, мне кажется, прекрасный это удел - пасть на войне» ${ }^{1}$. А. А. Тахо-Годи комментирует это высказывание так: «Знаменитые слова Сократа о прекрасной смерти в бою впоследствии в поэзии стали общим местом. Так, Гораций в одной из своих од (III 2,13$)$ пишет, что «красно и сладко умереть за отечество» (dulce et decorum est pro patrie mori)» ${ }^{2}$. С другой стороны, у Платона есть и критические оценки войны. Например, слова из второй книги Государства (373): «Пока мы еще ничего не станем говорить о том, влечет ли за собой война зло или благо, скажем только, что мы открыли происхождение войны - главный источник частных и общественных бед, когда она ведется» [12, с. 86].

Платон указывает, что войны часто используются тиранами как инструмент удержания власти. Война обеспечивает мобилизацию населения, что упрощает контроль над ним. В «Государстве» Сократ прямо говорит об этом: «Когда же он (тиран. - прим. А. К.-Л.) примирится кое с кем из своих врагов, а иных уничтожит, так что они перестанут его беспокоить, я думаю, первой его задачей будет постоянно вовлекать граждан в какие-то войны, чтобы народ испытывал нужду в предводителе... А если он заподозрит кого-нибудь в вольных мыслях и в отрицании его правления, то таких людей он уничтожит под предлогом, будто они предались неприятелю. Ради всего этого тирану необходимо постоянно будоражить всех посредством войны» [12, с. 296].

Все эти замечания верны, однако они остаются лишь частными заметками и не представляют собой философию войны Платона. Ни восхищение войной с поэтической и эстетической точки зрения, ни скепсис в отношении войны как инструмента для удержания власти тираном - ни вместе, ни по отдельности нельзя назвать философией войны.

Тема «Философия войны Платона» поставлена в науке достаточно давно. Западный исследователь Анджела Гоббс, например, в своей статье, посвященной как раз рассматриваемой нами теме, ставит интересный вопрос о том, сможет ли платоновское государство развиваться без войны: «Если поставить выбор между мирной жизнью без философии и военной жизнью с ней, то какая жизнь будет предпочтительнее?». Здесь западный исследователь ссылается на отрывок «Федона» (66 с.), и делает вывод, что раз большинство персонажей платоновских

\footnotetext{
${ }^{1}$ Платон. Менексен. URL: http://psylib.org.ua/books/plato01/05menek.htm (дата обращения: 19.11.2019). Текст: электронный.

2 Платон. Менексен // Платон. Диалоги. Москва: Мысль, 1986. Тимей. URL: http:/psylib.org.ua/books/plato01/05menek.htm (дата обращения: 19.11.2019). Текст: электронный.
} 
диалогов отрицательно судят о войне, то и сам Платон так же придерживается этой точки зрения. В том фрагменте «Федона», на который ссылается А. Гоббс, Сократ рассуждает о том, что настоящий философ должен отрешиться от телесного начала, поскольку с ним связаны страсти и искушения: «Тело наполняет нас желаниями, страстями, страхами и такой массой всевозможных вздорных призраков, что, верьте слову, из-за него нам совершенно невозможно о чем бы то ни было поразмыслить! А кто виновник войн, мятежей и битв, кто иной, как не тело и его страсти? Ведь все войны происходят ради стяжания богатств, а стяжать их нас заставляет тело, которому мы по-рабски служим. Вот по всем этим причинам - по вине тела - у нас и нет досуга для философии» (Федон, 66 C, D). Кроме этого фрагмента, А. Гоббс приводит также и другие места из диалогов Платона, в которых участники беседы в негативном ключе отзываются о войне (Государство 378 в-с, $547 \mathrm{e}-548 \mathrm{a}$ и др.). С нашей точки зрения, следует все-таки различать точку зрения персонажей платоновских диалогов, и точку зрения самого Платона, которая выражается, как правило, Сократом. Тем не менее А. Гоббс делает следующий вывод о платоновском отношении к войне: «Platos attitude to war is still that it is an evil, albeit an evil which can allow for the display and nurture of certain goods» [1, c. 179]. С нашей точки зрения, следует ставить вопрос не только о платоновском отношении к войне, но шире - о платоновской философии войны. По справедливому замечанию В. С. Соловьева, о войне надо ставить не один вопрос, но три: 1) о нравственном значении войны; 2) о ее значении в истории и 3) о моем личном отношении к войне, т. е. буквально: должен ли лично я идти на войну и защищать свое государство. Смешение этих трех вопросов - плод недомыслия, по Соловьеву. Рассмотрение же трех этих вопросов последовательно поможет составить целостное представление о философии войны у Платона. Платон эстетически (лично) мог оправдывать войну, любоваться ею, мог этически одобрять личное участие в войне гражданина, мог также осуждать войну, источник которой - телесные страсти, однако этим не исчерпывается философское отношение к войне.

Отечественный исследователь И. Н. Мочалова ставит вопрос об отношении Платона к войне схожим образом: «Может ли война быть оправдана? (о философии войны в контексте идеологии панэллинизма IV в. до н. э.) [7, с. 211]. Здесь исследователь делает, на наш взгляд, весьма поспешный вывод, который состоит в том, что Платон будто бы утверждает невозможность оправдать войну, поскольку она «разрушает подлинную природу человека» [7, с. 211].

Места, где война оценивается не только с этически негативной точки зрения, присутствуют, например, в Пире, когда Алкивиад рассказывает о доблести Сократа в бою, или в Менексене, когда Сократ говорит, что пасть на войне - это прекрасный удел. Впрочем, поскольку этот фрагмент Пира (и Менексена) являет собой, скорее, чисто художественное добавление к диалогу, то и похвалу военной доблести Сократа стоит отнести к эстетическому взгляду на войну у Платона.

Но у платоновского отношения к войне есть также гражданское и политическое измерение. Отсюда можно взять ответ и на первый, и на третий вопросы, которые, по Соловьеву, следует поставить о войне, т. е. на вопрос о нравственном значении войны и на вопрос о моем личном участии в войне. Так, в Тимее 
Сократ в своей речи коснется вопроса о том, как философы и софисты относятся к войне: «Что касается рода софистов, - говорит Сократ, - я, разумеется, всегда считал его весьма искушенным в составлении разнообразных речей и в других прекрасных вещах, но из-за того, что эти софисты привыкли странствовать из города в город и нигде не заводят собственного дома, у меня есть подозрение, что им не под силу те дела и слова, которые свершили и сказали бы в обстоятельствах войны, сражений или переговоров как философы, так и государственные люди» [13].

«В обстоятельствах войны», как мы видим, философу, по Платону, должны принадлежать особого рода слова и дела, на которые софист по своей странствующей (а не гражданской) природе не способен. Учитывая, как Платон описывает поведение Сократа на войне, а также зная о том, какую роль играет в Государстве Платона философы, можно не сомневаться, о каких делах и словах философа идет речь в этом отрывке: философ, отвечая на вопрос о личном соучастии в войне, отвечает положительно, т. е. как гражданин он может и должен принять участие в защите своего полиса, как это и демонстрируется примером Сократа. Поскольку ж защита полиса является делом благородным, и в этом деле возможно проявить такие добродетели, как мужество, рассудительность и справедливость, то здесь же заложен и ответ на первый вопрос - об общенравственном значении войны. Ответ этот состоит в том, что хотя война сама по себе происходит из низменной природы человека, она вместе с тем есть тот топос, внутри которого могут проявляться добродетели человека.

Для ответа на второй вопрос - об историческом значении войны - следует обратиться к платоновской типологии войн. О платоновской типологии войны и отношении к гражданским войнам уже достаточно сказано в исследовательской литературе [6] ${ }^{1}$. Напомним лишь коротко, что в «Государстве» Платон различает два вида войн: внешние войны (это войны с варварами) и внутренние (войны между эллинами, т. е. гражданские войны, их следует называть раздором). Если эллинам по природе свойственно воевать с варварами, то эллинами с эллинами воевать по природе не свойственно, по природе они друзья. Гражданские войны нарушают естественный уклад вещей и являются болезнью для всей Эллады. Соответственно Платон вырабатывает и два типа военной этики. В войне с внешним врагом эллинский воин должен проявлять мужество, главная цель - одолеть врага. Во внутренних же войнах недостаточно быть просто мужественным, поскольку это может и наемник, во внутренних войнах необходимо обладать «всей добродетелью в совокупности», т. е. обладать и мужеством, и справедливостью, и рассудительностью. Поскольку главная цель во внутренней войне не уничтожение врага, но мир в Элладе. Поскольку нельзя порабощать греков, то во внутренних войнах нет такой функции, как порабощение противника. Также во внутренних войнах запрещено сжигать поля и дома противника, поскольку этим самым грек опустошает свою собственную Родину.

${ }^{1} \mathrm{O}$ «справедливой войне» и «праве на войну» у Платона и Аристотеля рассуждает современный исследователь Е. В. Лобанов. 
Платоновское отношение к войне (собственно философия войны) станет еще более понятным, если обратится к его «Законам». Как выразился Р. Б. Евдокимов, «в море посвященной Платону литературы исследование «Законов» остается далеким и редко посещаемым заливом» [3, с. 191]. Между тем для понимая платоновской философии войны это сочинение крайне важно. Как известно, Платон в молодости одно время хотел посвятить себя политической деятельности, однако «афинская действительность рубежа V-VI вв. до н. э., наполненная кровавой политической борьбой, очень скоро разбила иллюзии лиричного по натуре юноши, и он отстранился от участия в государственных делах» - пишет В. П. Яйленко $[15$, c. 172]. И все же философская деятельность Платона привела его к решению воплотить свои проекты на практике. Это крайне важно при рассмотрении платоновской философии войны. Ведь одна из добродетелей философа по Платону - это бесстрашие. Чтобы решиться воплотить свой философский проект в жизнь необходимо бесстрашие. Платон мог бы остаться со своим первым проектом идеального государства, который, как должен был признать и сам мыслитель, был далек от реальной политической жизни. Платон мог бы остаться с поверхностным осуждением войны, и тогда многочисленные исследователи его взглядов на войну оказались бы правы. Но Платон тогда не был бы Платоном, великим философом. Как философ, он смотрит на феномен войны сложнее, нежели как стараются это представить исследователи.

В философии войны следует выделять несколько измерений, во-первых, этическое, затем политическое, в-третьих, экзистенциальное и в-четвертых, онтологическое, или космическое. Как правило, исследователи философии войны и сами философы войны видят только первые два измерения.

Оценка войны с нравственной точки зрения должна быть негативной: война есть зло. С политической точки зрения война рассматривается в контексте своих причин и итогов. Когда говорят о справедливой войне, то чаще всего стремятся дать этические нормативы, которые могут использоваться в политике. Отсюда многочисленные теории справедливой войны. Западной философии войны свойственно как раз работать в первых двух измерениях, тогда как русская философия войны сосредоточена более на экзистенциальном измерении войны, ее преображающем действии (война как экзистенциал для русских философов), и на историческом (т. е. вопрос о роли войны в человеческой истории).

У Платона мы находим этическое измерение войны: причина войн страсти тела, войны ведутся ради обогащения. Находим измерение политическое: война есть главное действие/движение государства. За экзистенциальное измерение войны можно принять поэтику войны, присутствующую в некоторых диалогах Платона (рассказ Алкивиада в Пире о доблести Сократа на войне, слова Сократа в Менексене о том, что пасть на войне это прекрасный удел и т. д.; в конце концов, сама обращенность Платона на тему войны обусловлена личным опытом философа, чье взросление пришлось на Пелопонесскую войну и на глазах у которого его родной полис был повержен). Имеется у Платона и онтологическое (космологическое) измерение войны. Так, в первой книге «Законов» Афинянин описывает устройство полиса и затем заключает (625-626): «Все это у нас приспособлено к войне, и законодатель, по-моему, установил все, принимая в сооб- 
ражение именно войну... Он заметил, я думаю, неразумие большинства людей, не понимающих, что у всех в течение жизни идет непрерывная война со всеми государствами... Ибо то, что большинство людей называет миром, есть только имя, на деле же от природы существует вечная непримиримая война между всеми государствами» [11]. Далее Афинянин делает вывод, что все и частные, и общественные учреждения как таковые существуют ради войны, потому что «никакое достояние, никакое занятие, вообще ничто не принесет никому пользы, если не будет победы на войне: ибо все блага побежденных достаются победителю» [11].

Однако рассуждение Платона не останавливается на этом, и философ прямо онтологизирует войну, подобно Гераклиту, и утверждает, что война ведется не только между государствами, но и между людьми, и даже в самом человеке непрерывно идет война. В Законах Афинянин говорит (626-627): «Но разъясни мне еще вот что: из данного тобой определения с благоустроенного государства вытекает, насколько я могу судить, что его надо устроять так, чтобы оно побеждало на войне остальные государства. Не так ли? ...Но это положение, верное для взаимоотношений государств, не может ли оказаться иным, когда речь пойдет об отношениях поселков? ...Оно одинаково в приложении к отношениям и между двумя домами одного поселка, и между двумя людьми? ...Должен ли думать каждый человек, что он сам себе враг, или не должен?» [11].

На это его собеседник, Клиний, отвечает, что, действительно, каждый человек борется внутри себя с самим собой, и что «победа над самим собой есть первая и наилучшая из побед. Быть же побежденным самим собой всего постыднее и хуже. Это и показывает, что в каждом из нас происходит война с самим собой» $[11]$.

Таким образом, философия войны Платона представляет собой сложную систему со многими измерениями, без учета каждого из которых невозможно составить целостное измерение платоновской философии войны. Объявлять Платона противником войны как таковой настолько же неверно, как представлять себе античного философа ярым милитаристом. Философское сознание Платона принимало войну как мировую данность, однако даже идеальное платоновское государственное устройство предполагает войну как государственную функцию, без которой существование государства невозможно. При анализе платоновских представлений о войне нельзя исходить из одних лишь его текстов, но следует учитывать исторический контекст их написания. Философское отношение к войне включает в себя несколько измерений (этическое, онтологическое, историческое и т. д.), ни одно из которых не может претендовать на универсальность. Анализ платоновской философии войны показывает, что в творчестве Платона присутствуют все эти измерения, и лишь собрав их воедино, можно получить целостное представление об отношении философа к такому феномену, как война.

Лumepamypa

1. Hobbs A. Platoonwar. Maieusis. Essayson Ancient Philosophy in Honour of My les Burnyeat. Edited by Dominic Scott. Oxsford: Universitypress, 2007. 425 p.

2. Гераклит Эфесский. Все наследие на языках оригинала. Москва: Ад Маргинем Пресс, 2012. 416 с. Текст: непосредственный. 
3. Евдокимов Р. Б. Должностные лица в идеальном государстве платоновых «Законов» // Платон и его эпоха. К 2400-летию со дня рождения. Москва: Наука, 1979. С. 191-211. Текст: непосредственный.

4. Ивонин Ю. П., Ивонина О. И. Политическая антропология Платона // Идеи и идеалы. 2019. Т. 11, № 1-1. С. 103-126. Текст: непосредственный.

5. Ксенофонт. Анабасис Греческая история. Москва: Издательство АСТ: Ладомир, 2013. 640 с. Текст: непосредственный.

6. Лобанов Е. В. Платон и Аристотель о войне // Знание. Понимание. Умение. Москва, 2015. № 1. С. 304-310. Текст: непосредственный.

7. Мочалова И. Н. Может ли война быть оправдана? (о философии войны в контексте идеологии панэллинизма IV в. до н. э.) // Вестник ленинградского государственного университета им. А. С. Пушкина. 2010. Т. 2, № 2. С. 211-221. Текст непосредственный.

8. Платон. Избранные диалоги / перевод с древнегреческого А. Егунова; составитель, вступительная статья и комментарии В. Асмуса. Москва: Художественная литература, 1965. 442 с. Текст: непосредственный.

9. Платон. Законы. Послезаконие. Письма. Санкт-Петербург: Наука, 2014. 517 с. Текст: непосредственный.

10.Платон. Законы. URL: http://psylib.org.ua/books/ plato01/30zak01.htm (дата обращения: 19.11.2019). Текст: электронный.

11.Платон. Ион, Протагор и другие диалоги / ответственный редактор, составитель Я. А. Слинин. Санкт-Петербург: Наука, 2014. URL: http://psylib.org.ua/books/ plato01/05menek.htm (дата обращения: 12.12.2019). Текст: электронный.

12.Платон. Государство / перевод с древнегреческого А. Н. Егунова; вступительная статья Е. Н. Трубецкого; комментарии В. Ф. Асмуса; примечание А. А. Тахо-Годи. Москва: Академический проект, 2015. 398 с. Текст: непосредственный.

13.Платон. Тимей. URL: http://psylib.org.ua/books/ plato01/27timei.htm (дата обращения: 12.12.2019). Текст: электронный.

14.Плотин. Третья Эннеада / перевод с древнегреческого Т. Г. Сидаша; вступительная статья Т. Г. Сидаша и Ю. Д. Сухова. Санкт-Петербург: Издательство Олега Абышко, 2004. 374 с. Текст: непосредственный.

15. Яйленко П. В. Платоновская теория обоснования полиса и эллинская колонизационная политика. Платон и его эпоха. К 2400-летию со дня рождения. Москва: Наука, 1979. С. 172-190. Текст: непосредственный.

Статья поступила в редакичию 16.06.2021; одобрена после рецензирования 05.07.2021; принята к публикацุии 14.09.2021.

\section{PLATO'S PHILOSOPHY OF WAR}

Andrey Yu. Korobov-Latyntsev

Cand. Sci. (Philos.),

Head of Humanities Department, Lieutenant,

Donetsk Higher Combined Arms Command School

Donetsk, Donetsk People's Republic

a.k-1@mail.ru

Abstract. The article reconstructs Plato's philosophy of war. The growing up of the famous idealist philosopher took place during the war of his native polis with Sparta, therefore the 
problem of the germ and nature of war occupies an important place in his philosophy. This is reflected in his constructions about the state, in the ethics, and even in his ideas about the human nature. According to Plato, in war the state appears in motion. The philosopher divides wars into external (the wars with the barbarians) and internal (the wars of the Greeks with each other). He considers internal wars using ethical criteria, at the same time external wars are discussed on completely different grounds. Plato regards not only the political and ethical dimension of war, but also the ontological one.

Keywords: Plato, the philosophy of war, internal and external wars, virtue.

\section{For citation}

Korobov-Latyntsev A. Yu. Plato's Philosophy of War. Bulletin of Buryat State University. Philosophy. 2021; 3: 27-35 (In Russ.).

The article was submitted 16.06.2021; approved after reviewing 05.07.2021; accepted for publication 14.09.2021. 